This item was submitted to Loughborough's Research Repository by the author.

Items in Figshare are protected by copyright, with all rights reserved, unless otherwise indicated.

\title{
MIMO control of a turbogenerator for energy recovery
}

PLEASE CITE THE PUBLISHED VERSION

https://doi.org/10.4271/2020-01-0261

PUBLISHER

SAE International

VERSION

AM (Accepted Manuscript)

PUBLISHER STATEMENT

This paper was accepted for publication in SAE Technical Papers and the definitive published version is available at https://doi.org/10.4271/2020-01-0261.

\section{LICENCE}

CC BY-NC-ND 4.0

\section{REPOSITORY RECORD}

Petrovich, Simon, Kambiz Ebrahimi, Nikolaos Kalantzis, and Antonios Pezouvanis. 2020. "MIMO Control of a Turbogenerator for Energy Recovery". Loughborough University. https://hdl.handle.net/2134/14150015.v1. 


\title{
MIMO Control of a Turbogenerator for Energy Recovery
}

\author{
Simon Petrovich, Kambiz Ebrahimi, Nikolaos Kalantzis, and Antonios Pezouvanis \\ Loughborough University
}

\begin{abstract}
Market trends for increased engine power and more electrical energy on the powergrid $(3 \mathrm{~kW}+)$, along with customer demands for fuel consumption improvements and emissions reduction, are driving requirements for component electrification, including turbochargers. GTDI engines waste significant exhaust enthalpy; even at moderate loads the WG (Wastegate) starts to open to regulate the turbine power. This action is required to reduce EBP (Exhaust Back Pressure). Another factor is catalyst protection, where the emissions device is placed downstream turbine. Lambda enrichment or overfueling is used to perform this. However, the turbine has a temperature drop across it when used for energy recovery. Since catalyst performance is critical for emissions, the only reasonable location for an additional device is downstream of it. This is a challenge for any additional energy recovery, but a smaller turbine is a design requirement, optimized to operate at lower pressure ratios. A WAVE model of the 2.0L GTDI engine was adapted to include a TG (Turbogenerator) and TBV (Turbine Bypass Valve) with the TG in a mechanical turbocompounding configuration, calibrated with steady state dynamometer data. This includes power and fuel consumption, and additionally a sensitivity analysis and knock impact assessment. Further work includes transient verification with WAVE-RT on WLTP and RDE drive cycles, estimating dynamic energy recovery, assessing electrical turbocompounding, interfacing to the powergrid, and calibration optimisation, using combined WG and TBV settings. Development of more advanced MIMO (Multiple-Input, Multiple-Output) control system algorithms and prototype testing on dynamometer or vehicle could be performed to verify design assumptions and simulation results.
\end{abstract}

\section{Introduction}

Exhaust energy is wasted on modern ICE's (Internal Combustion Engines). Some engines are NA (Naturally Aspirated) and have no form of energy recovery, but for some, a turbocharger recovers some energy, but still a lot wasted ("wastegated"). Some is required for aftertreatment heating modes or purges. Effectively, the ICE is used as exhaust temperature controller. On modern GTDI's, the exhaust power downstream the turbine can be several $\mathrm{kW}$ and $\mathrm{WG}$ opening is quite significant, signifying that as well as back pressure reduction, energy is wasted!

Turbogenerators have been studied for decades [1]. Indeed, heavy duty trucks already have TG's $[2,3]$ but also turbocompounding (direct connection to crankshaft, mechanically) so this concept is not new. Smaller powerpacks are being considered, for example a dieselpowered bus $[4,5]$, but only at selected speeds and loads. However,

Page 1 of 6 the work based on the NEDC, which is reasonably light load, but new WLTP and/or RDE [6] drive cycles which have higher loads, therefore more enthalpy will be wasted. A better case to study is passenger cars in which there is more opportunity for mechanical to electrical energy conversion via energy recovery.

On gasoline engines, the engine back pressure is a key constraint since not only temperature but pressure ratio is a requirement over the turbine, via the power equation. This also has an impact for internal EGR (Exhaust Gas Recirculation, via residual gas fraction control), fuel consumption and performance.

In order to increase the overall system efficiency, electrification of the turbocharger could be considered, but this is not considered for mainstream programs at most OEM's. However, it opens up system integration opportunities for on-board power generation, supporting running more electric propulsion mode operation, for example in full hybrids [7].

Figure 1 shows a description of the family of turbocompounding developed over the years. It can be seen that most of the turbocompounding units (Cummins Inc., Iveco S.p.A, Caterpillar Inc., John Deere and Bowman Power Group Ltd) have been developed to recover exhaust energy for large ICE's. So far only CPT (Control Power Technologies, now part of Tenneco) has tried to implement electrical turbocompounding for small capacity ICE's and therefore this provides an opportunity to develop novel concepts/design solutions for turbocompounding engines in the small/medium car segment.

Further extensions include eBoosters (electric compressors) with energy recovery [8] and decoupled eChargers Aeriston ("Fully Electric Turbocharger Technology" or FETT) [9].

Moreover, comparing EAT's (Electric Assist Turbochargers) vs. TG's, only the former can improve transient performance. The EAT can be used a normal turbocharger when required. However, both have recovery potential, but deleting the WG or alternator is not possible [10]. However, integration complexity is less for the TG case and it can be fitted as an aftermarket device. 


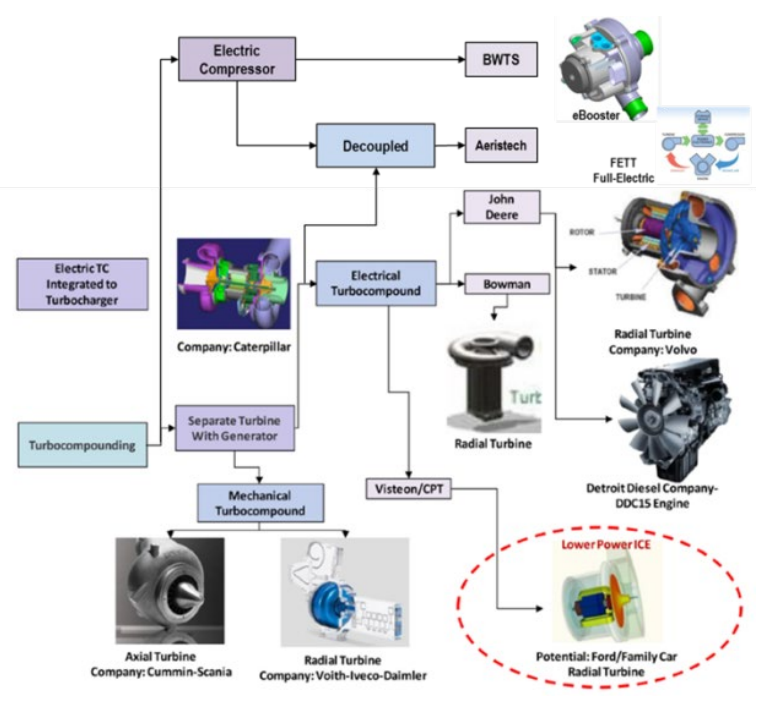

Figure 1: Family of turbocompounding.

The exhaust TG (power turbine downstream of turbocharger) compounded to the engine crankshaft is one technology (either in mechanical or electric turbocompound configuration).

Recoverable energy depends on many factors (e.g., engine size \& type, nature of application/drive cycle) and varies strongly across engine operating range.

The problem statement is: determine the drive cycle $\mathrm{FC}[\%]$ and energy recovery potential $[\mathrm{kW}]$ of new technology turbogenerator using drive cycle residency analysis.

\section{System Design and Basic Analysis}

This section summarises the basic theoretical analysis and gives an insight into the hardware design.

\section{Brake Efficiency}

For a typical 2.0L GTDI powered vehicle, typical efficiency (clutch power/fuel power, Figure 2). At mid-loads (up to 12 bar BMEP), the WG is still closed, so for system with no modification, there is no benefit on NEDC or WLTP.

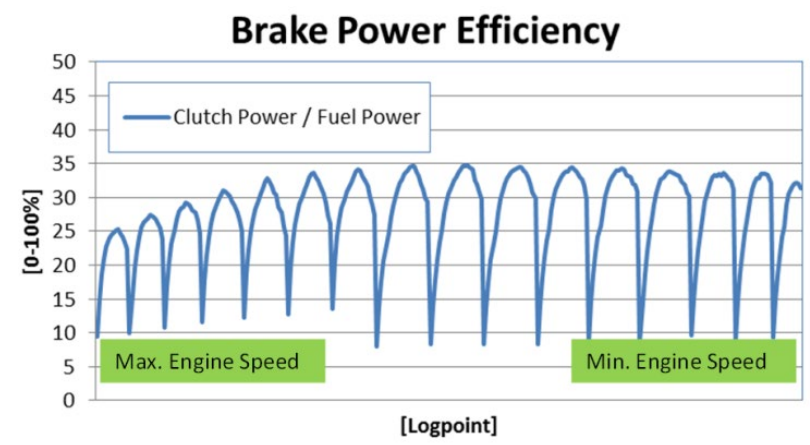

Figure 2: Steady state engine efficiency.

\section{Theoretical Analysis}

The available thermodynamic power for the TG device can be calculated as follows:

$P_{T G}=c_{p} m_{e x h} T_{C A T} \eta_{T G}\left(1-\left(P_{d n} / P_{u p}\right)^{\frac{\gamma-1}{\gamma}}\right)$

with the symbols:

$\begin{array}{ll}\text { P_TG : } & \text { Thermodynamic power/[W] } \\ \text { c_p } \quad: & \text { Specific heat capacity at constant } \\ \text { pressure } /[\mathrm{J} / \mathrm{kgK}] & \end{array}$

m_exh : $\quad$ Exhaust flow $/[\mathrm{kg} / \mathrm{s}]$

T_CAT : $\quad$ Catalyst outlet temperature/[K]

$\eta \_$TG $\quad: \quad$ Total-to-static efficiency/[0-1]

$\gamma \quad: \quad$ Ratio of specific heats/[-]

P_dn/P_up: $\quad$ Downstream/upstream pressure ratio/[-]

Figure 3 shows the pressure post catalyst and the potential turbogenerator power from the steady state engine mapping data, assuming no airpath calibration modifications and a TG efficiency of $50 \%$. Several $\mathrm{kW}$ of thermodynamic power is possible, but note the maximum pressure post catalyst is very low at $1180 \mathrm{mbar}$ at $6500 \mathrm{rpm}$.
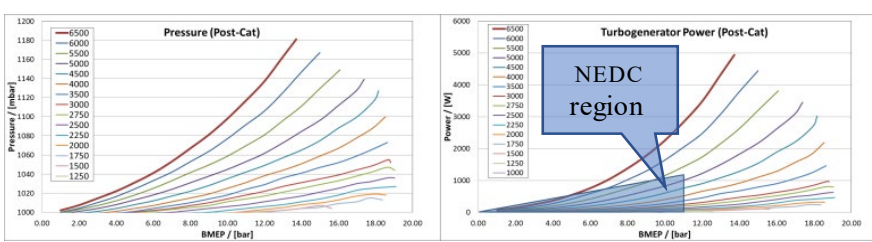

Figure 3: Pressure and potential thermodynamic power available post catalyst.

\section{Hardware Configuration and Design}

The LPT (Low Pressure Turbine) was designed to fill the existing technology gap where no commercially available turbines can operate effectively at low-pressure ratios (1.05 to 1.3) to drive an electric generator with a targeted $1.0 \mathrm{~kW}$ power output with $50 \mathrm{krpm}$ as the initial speed design target. The newly designed LPT geometry was tested at Imperial College London (ICL) under steady-state conditions; a maximum total-to-static efficiency, $\eta_{\mathrm{TS}}=75.8 \%$ at pressure ratio, $\mathrm{PR}=1.08$ was found.

A further variant of the LPT design was used in subsequent analysis for the representative 2.0L GTDI engine, with a higher speed and 
scaled flow parameter. The peak total-to-static efficiency of $70 \%$ occurs in the range of 1.05-1.1, as in Figure 4.
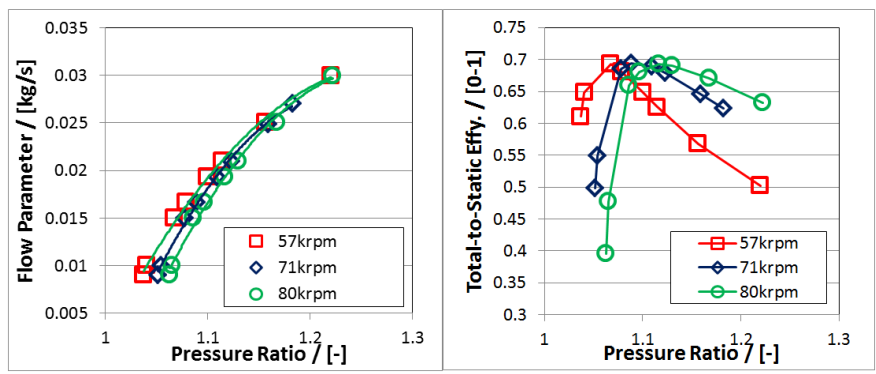

Figure 4: Turbine performance maps. Flow (left) and efficiency (right).

References [11], [12] give a more detailed background.

\section{Controls and Modelling}

The 1-D simulation environment was set up in Ricardo WAVE [13] and included the LPT downstream the catalyst with a continuously variable bypass. There were 2 control loops: throttle controlling the BMEP and the WG controlling the intake manifold pressure. The engine has VVT (Variable Valve Timing) and the exhaust valve phasing was used to control the residues (internal EGR) to a setpoint, but there was no additional intake/exhaust valve optimisation. The LPT was connected in a mechanical compounding configuration, with a defined gear ratio, meaning the additional thermodynamic power was added directly to the engine with a mechanical efficiency of $90 \%$, and not to an external electrical device (electrical turbocompounding). Due to the peak efficiency occurring at about 1.1-1.15 for higher LPT speeds, the TBV controller was set to control to an LPT PR of 1.15. Knock impact was additionally considered. Figure 5 shows the generic electrified GTDI model schematic, illustrating the TG connected to a motor/generator $(\mathrm{M} / \mathrm{G})$ and an optional Energy Storage System (ESS). The turbochargers are of type FGT (Fixed Geometry) with a bypass valve.

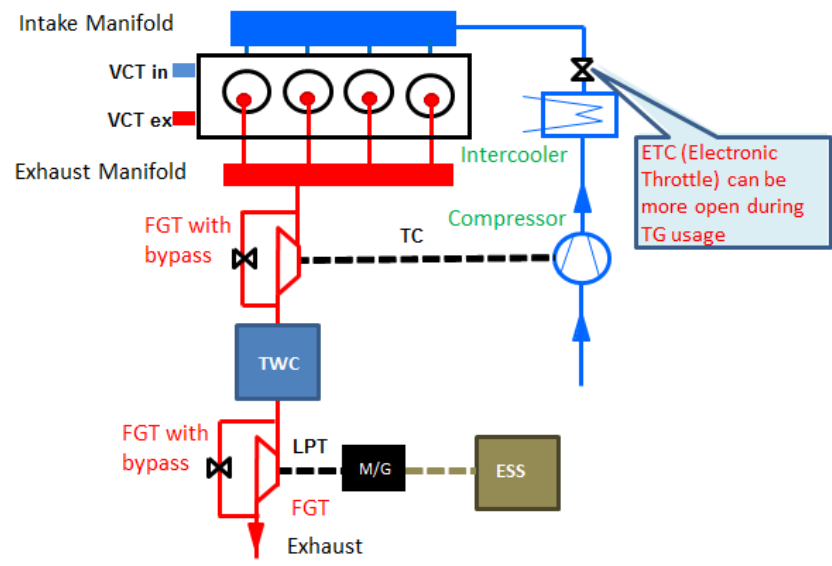

Figure 5: Schematic diagram of the GTDI model.

In order to validate the model versus real-world engine mapping data, several parameters were matched, catalyst outlet temperature, BSFC, as well as turbine and compressor conditions. The residuals did not exceed $25 \%$.

\section{Multivariable System}

Considering the main system inputs and outputs, it is clear there are interactions, hence the system is a multivariable one (MIMO, MultiInput, Multi-Output). In a base configuration with TBV fully open, the TG produces no additional thermodynamic power. However, as the TBV closes, exhaust gas is forced through the TG, recovering more power, which increases the exhaust back pressure. In such instances the throttle can be opened more which affects the intake conditions.

Interaction analysis using RGA (Relative Gain Array) can decide the best input/output pairing [14], employing off-diagonal terms.

However, modern controller methods can use tuning via non-smooth $\mathrm{H}_{\infty}$ synthesis method as in [15] which takes into account internal couplings [16]. Soft objectives (settling time and steady state error) and hard constraints (gain and phase margin) are performance targets.

Further, in order to make best use of engine operating conditions, the controller gains can be parametrized as a function of frequency, $\omega$, in order to best control the system on fast transients such as tip-ins and steady state operation, in Figure 6 and Equation 2. Such a MIMO based structure can take into account couplings or interactions and improve the controller performance, thereby improving fuel economy and emissions.

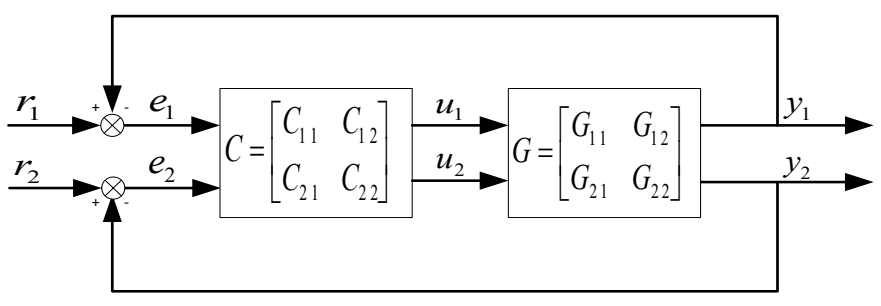

Figure 6: Generic 2x2 multivariable control system with interactions.

$C_{i j}=C_{i j}(j \omega), G_{i j}=G_{i j}(j \omega)$

$r$ represents the reference setpoint, $e$ the error, $u$ the actuator input, $y$ the measured output. The controller is $C$ and the plant $G$.

In the system under consideration, the actuators are the throttle angle, $\mathrm{TBV}$, and the wastegate, with the system outputs boost pressure, throttle inlet pressure and turbogenerator power, i.e. a $3 \times 3$ system.

\section{Controller Requirements}

Based on normal engine operating modes use cases, a set of requirements can be determined, in Table 1; for example, on braking events, the LPT bypass can be fully closed to make maximum use of regenerative energy, depending on the SOC (State of Charge), in a configuration with an ESS. 


\begin{tabular}{|l|l|l|l|l|l|}
\hline Engine State & $\begin{array}{l}\text { Low } \\
\text { Load }\end{array}$ & $\begin{array}{l}\text { Mid to } \\
\text { High Load }\end{array}$ & Braking & Stop/Start & $\begin{array}{l}\text { Emissions } \\
\text { Mode }\end{array}$ \\
\hline TG Control Mode & FO & $\begin{array}{l}\text { Control to desired } \\
\text { pressure ratio }\end{array}$ & FC & FO & $\begin{array}{l}\text { FC to improve } \\
\text { warmup }\end{array}$ \\
\hline Limitation & N/A & $\begin{array}{l}\text { SOC limit, } \\
\text { e-machine torque } \\
\text { and temperature }\end{array}$ & $\begin{array}{l}\text { SOC limit, } \\
\text { e-machine } \\
\text { speed }\end{array}$ & N/A & $\begin{array}{l}\text { SOC limit, } \\
\text { FO for GPF } \\
\text { regeneration }\end{array}$ \\
\hline
\end{tabular}

Table 1: Turbogenerator operating modes $(\mathrm{FC}(\mathrm{O})=$ Fully Closed (Open)).

Further emissions modes are more complex and depend on the aftertreatment layout. A GPF (Gasoline Particulate Filter) regeneration would require a FO setting, to maximize the heat flux, but this depends on the regeneration strategy employed.

\section{Simulation and Results}

The simulation results consist of 3 parts, namely drive cycle analysis, sensitivity and knock investigation.

\section{Drive Cycle}

Indicative steady state results have been shown in [12]. Summarising, 16 Key Points (KPs) were selected with the highest time residency on the NEDC, for example, 2500rpm/10bar on the extra-urban phase. However, vehicle homologation requires a transient test, the one in operation at the time for the representative 2.0L GTDI vehicle was the NEDC. Reusing the 1-D model (as described in [12]), with some minor changes, from a representative vehicle test and these were used for subsequent steady state simulations [12], where BMEP is Brake Mean Effective Pressure. The results were extrapolated in order to be able to predict for a complete $1180 \mathrm{~s}$ drive cycle. The thermodynamic power was calculated using Equation 1.

Some KPs have a detrimental BSFC impact: here the TBV should be open (use LPT only for thermodynamic power $>50 \mathrm{~W}$, for example)

- $\quad$ Max. 2.3\% FC improvement and $1.2 \mathrm{~kW}$ shaft power at KP16 (2500rpm/11bar BMEP)

- $\quad$ Average 45W LPT shaft power and $0.3 \%$ FC improvement (TBV fully closed) over the whole cycle

- Modest exhaust back pressure increase

N.B. No modifications to WG or VVT.

In order to put the recovered power into perspective, the average measured generated electrical power for the vehicle on-cycle (1180s) was approximately $135 \mathrm{~W}$. This figure depends strongly on the powergrid configuration, and TG performance can be further improved using advanced control algorithms.
BSFC IMPROVEMENT DUE TO LPT [\%] vs KP
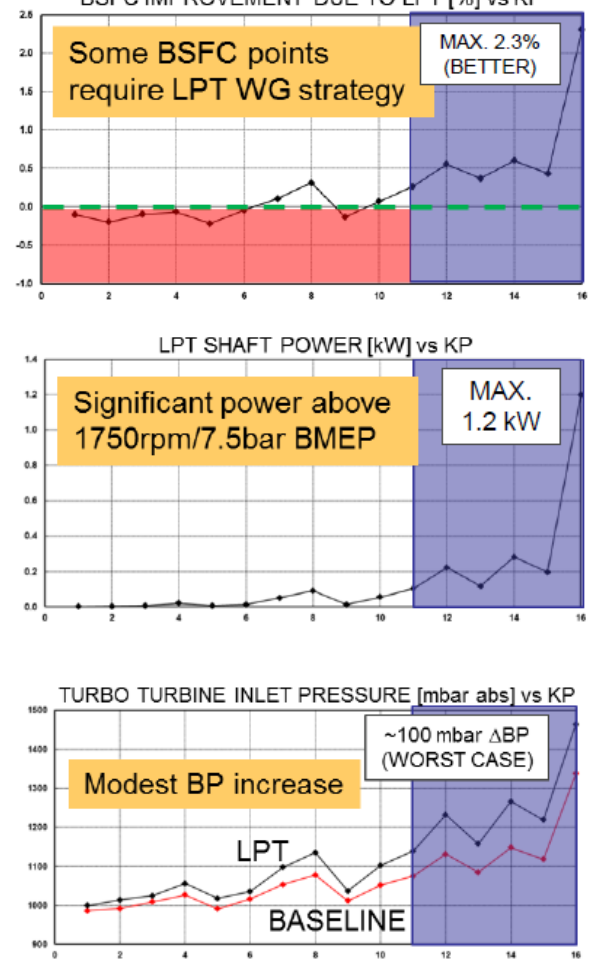

Figure 7: 16 KP summary: top BSFC improvement, middle shaft power, bottom EBP increase.

\section{Sensitivity}

The extrapolated NEDC KP's showed significant LPT power only at higher loads. In order to look further at the 2500rpm case and at a WLTC capability, an additional separate 3000rpm/13bar BMEP KP was selected, with no constraint on the LPT PR. The LPT WG was increased from $0 \%$ (fully closed) to fully open $(50 \mathrm{~mm})$ in steps of $10 \mathrm{~mm}$.

Whilst the peak thermodynamic powers are $2.25 \mathrm{~kW}$ and $3.63 \mathrm{~kW}$ for $2500 \mathrm{rpm} / 11$ bar and $3000 \mathrm{rpm} / 13 \mathrm{bar}$, respectively (Figure 8(a)), it should be noted that the peak LPT efficiencies occur at about 20 $30 \mathrm{~mm}$ LPT WG opening (not shown in Figure 8), but the LPT PR is quite large (plot (c)). Note, the available, useable power will be less than this due to system losses. The BSFC (plot (b)) is lower when the LPT WG is near to closed, increasing to 250.95 (2500 rpm) and $247.9(3000 \mathrm{rpm}) \mathrm{g} / \mathrm{kWhr}$, whereas the mapped engine values are 244.79 and $248.89 \mathrm{~g} / \mathrm{kWhr}$, respectively. Hence, it is still advantageous to generate thermodynamic power at higher engine speeds, but an optimal LPT WG setting may be required, which drives the control system requirements. Note, the LPT speed was 96 $\mathrm{krpm}$ at the $3000 \mathrm{rpm}$ point and drives a component redesign for higher-loaded driver cycles (there is a fixed gear ratio from TG to crankshaft in mechanical turbocompounding configuration). 


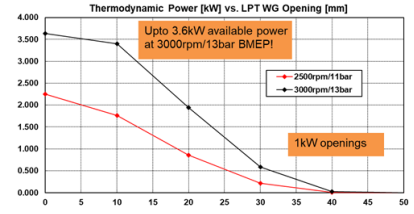

(a)

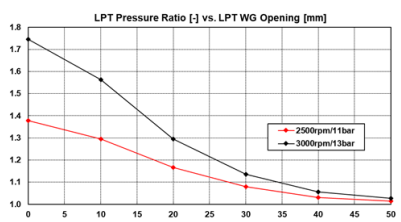

(c)

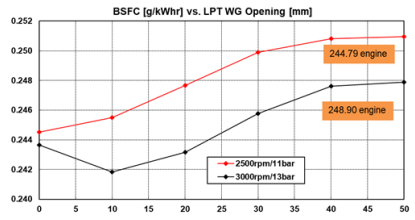

(b)

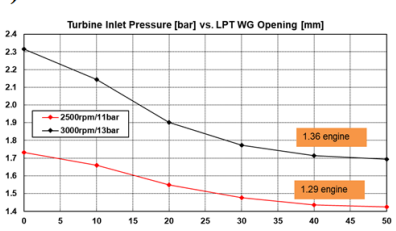

(d)

Figure 8: Sensitivity analysis vs. LPT WG opening. (a) Thermodynamic power, (b) BSFC, (c) LPT pressure ratio, (d) LPT inlet pressure.

\section{Knock}

Knock simulations are based on Douaud and Eyzat's induction time correlation [17].

For a knock assessment, the speed/load settings were selected in Section Sensitivity: both the residuals $(0-25 \%)$ and LPT WG $(0-$ $30 \mathrm{~mm}$ ) were varied. Knock intensity is defined as amount of unburned fuel mass divided by the total mass (normalized mass fraction) as consumed by the knock event.

Conclusion: there is no significant knock impact (LPT+CA50, crank angle at 50\% fuel mass burn, Figure 9).

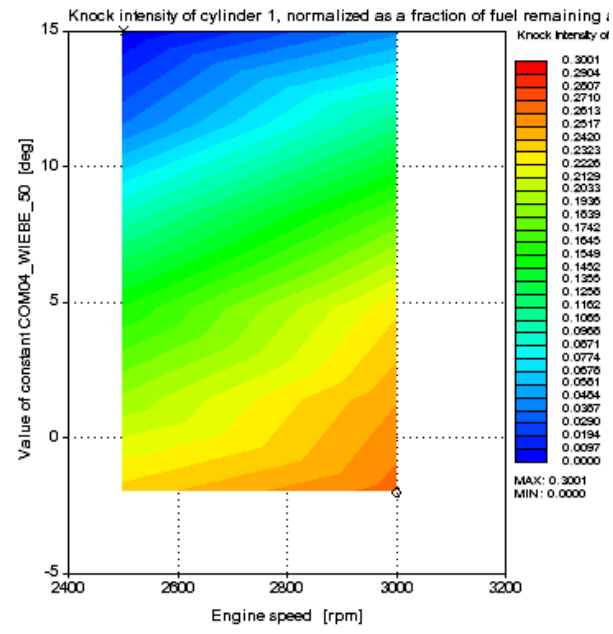

Figure 9: Knock assessment on cylinder 1 for residual/LPT WG sweep.

\section{Summary and Conclusions}

Potential for EWHR using an LPT specifically design for low pressure ratios was simulated on 2.0L GTDI engine model. Upscaling of LPT technology $(1.0 \mathrm{~L}->2.0 \mathrm{~L})$ suggests a similar maximum $\mathrm{BSFC}$ reduction is possible $(\sim 2.3 \%)$, however the NEDC extra-urban KPs indicate that the LPT could be used as co-generating device in addition to alternator, but the total on-cycle power/fuel consumption improvement is about a $40 \mathrm{~W} / 0.3 \% \mathrm{FC}$ improvement.

A turbine Bypass Valve (TBV) is a requirement to alleviate negative BSFC impact due to pumping work (low exhaust energy $<50 \mathrm{~W}$ shaft power) and to fulfill further engine operating mode requirements.

Higher power recovery $(\sim 3.6 \mathrm{~kW})$ is possible, while maintaining net BSFC benefit, can be attained if EBP is increased at high loads (offNEDC), making use of a TBV, but higher speed required than the $80 \mathrm{krpm}$ design.

There is no significant knock impact up to about 3000rpm/13bar BMEP, with a full TBV sweep.

Turbogenerators are an enabler for both hybridisation (e.g. power balance for eBooster usage) and conventional combustions systems (e.g. external EGR, increasing EBP for increased flow).

Further work: VVT and WG/TBV transient optimisation, including controls development.

\section{References}

1. Lampérth, M., Pullen, K. and Mueller, K. "Turbogenerator Based Hybrid Versus Dieselelectric Hybrid - A Parametric Optimisation Simulation Study," SAE Paper 2000-01-3100, Imperial College of Science, Technology \& Medicine, 2000.

2. Patterson, A. T. C, Tett, R. J., McGuire, J. Exhaust Heat Recovery using Electro-Turbogenerators, SAE Paper 2009-011604, Bowman Power, 2009.

3. Vuk, Carl T. "Turbo Compounding: A Technology Whose Time Has Come," 25 August, 2005 John Deere Moline Technical Center

4. Briggs, I., McCullough, G. S., Stephen, D., Douglas, R., O'Shaughnessy, R., Hanna, A., Rouaud, C., "Waste Heat Recovery on a Diesel-Electric Hybrid Bus Using a Turbogenerator," SAE Paper 2012-01-1945, 2012.

5. Briggs, I., Mccullough, G., Douglas, R., Spence, S., "Modelling waste heat recovery with a turbogenerator on a diesel engine," Ricardo European User Conference, Queen's University Belfast, 27th March 2012

6. Emission cycle tests, http://www.dieselnet.com/standards/cycles.

7. Lee, W., Schubert, E., Li, Y., Li, S. et al, "Electrification of Turbocharger and Supercharger for Downsized Internal Combustion Engines and Hybrid Electric Vehicles-Benefits and Challenges," DOI: 10.1109/ITEC.2016.7520254, 2016.

8. BorgWarner eBooster® "Electrically Driven CompressorElectric Boosting for Improved Fuel Economy," Knowledge Library, 2017.

9. Richards, B. "Developing a Full Electric Turbocharger to Achieve Decoupling of the Turbine and Compressor for Heavy Duty Diesel Engines," Aeriston, SIA, 2016.

10. Dimitriou, P., Burke, R., Zhang, Q., Copeland, C., Stoffels, H., "Electric Turbocharging for Energy Regeneration and Increased Efficiency at Real Driving Conditions," Applied Sciences, 1 April 2017.

11. Bin Mamat, A.M.I., Martinez-Botas, R.F., "Characterization of a low pressure turbine for turbocompounding applications in a heavily downsized mild-hybrid gasoline engine," Energy 64:316. January 2014. 
12. Bin Mamat, A.M.I., Martinez-Botas, R.F., Rajoo, S., Romagnoli, A., et al, "Waste heat recovery using a novel high performance low pressure turbine for electric turbocompounding in downsized gasoline engines: Experimental and computational analysis," Energy, Volume 90, Part 1, October 2015, Pages 218234.

13. Ricardo WAVE, http://www.ricardo.com/en-GB/What-wedo/Software/Products/WAVE

14. Skogestad, S., Postlethwaite, I., "Multivariable Feedback Control Analysis and design," John Wiley \& Sons, 2005.

15. Zhao, D., Winward, E., Stobart, R., Steffen, T., "Characterisation, control, and energy management of electrified turbocharged diesel engines," Energy Conversion and Management, March 2017.

16. Apkarian, P., Noll, D., "Non-Smooth Hळ Synthesis," I.E.E.E. Transactions on Automatic Control, 2006;51(1):71-86.

17. Douaud, A. M. and Eyzat, P., "Four-Octane-Number Method for Predicting the Anti-Knock Behavior of Fuels and Engines," SAE Paper 780080, 1978.

\section{Contact Information}

Author: Simon Petrovich

E-Mail: $\underline{\text { S.Petrovich@lboro.ac.uk }}$

Author: Professor Kambiz Ebrahimi

E-Mail: K.Ebrahimi@,1boro.ac.uk

Author: Dr. Antonios Pezouvanis

E-Mail : $\underline{\text { A.Pezouvanis@,1boro.ac.uk }}$

Author: Dr. Nikaos Kalantzis

E-Mail : N.Kalantzis@1boro.ac.uk

Address: Aeronautical and Automotive Engineering, Loughborough University, Stewart Miller Building, LE11 3TU Loughborough, United Kingdom

\section{Acknowledgments}

Thank you to Alessandro Romagnoli / Nanyang Technological University / Singapore, Professor Ricardo F Martinez-Botas, Dr
Aaron Costall / Imperial College, UK, Aman MI Bin Mamat / Universiti Teknologi MARA / Malaysia for the original collaboration opportunity.

\section{Definitions/Abbreviations}

BMEP: Brake Mean Effective

Pressure

BSFC: Brake-Specific Fuel

Consumption

EBP: Exhaust Back Pressure

FC: Fuel Consumption

GTDI: Gasoline Turbocharged

Direct Injection

KP: Key Point

LPT: Low-Pressure Turbine
NEDC: New European Drive

Cycle

PR: Pressure Ratio

RDE: Real Driving Emissions

RGA: Relative Gain Array
WG: Wastegate

WLTP: Worldwide

Harmonised Test Procedure 